\title{
COMPARISON OF TWO POSTERIOR INSTRUMENTATION TECHNIQUES IN MULTILEVEL CERVICAL SPONDYLOTIC MYELOPATHY TREATMENT: LATERAL MASS SCREW FIXATION VS PEDICLE SCREW FIXATION
}

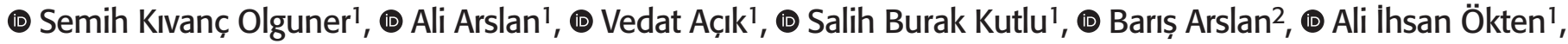 \\ (D) Yurdal Gezercan ${ }^{1}$ \\ ${ }^{1}$ Adana City Training and Research Hospital, Clinic of Neurosurgery, Adana, Turkey \\ ${ }^{2}$ Adana City Training and Research Hospital, Clinic of Anesthesiology, Adana, Turkey
}

\begin{abstract}
Objective: In this study we compared the clinical results of two posterior instrumentation methods in surgical treatment of multilevel cervical spondylotic myelopathy (CSM) and we aimed to share the clinical outcomes.

Materials and Methods: This study was a retrospective analysis of patients with multilevel CSM disease who underwent decompression and posterior internal fixation with lateral mass screw (LMS) or pedicle screw (PS). The study included 63 patients and the patients were divided into two groups. The LMS group comprised 32 patients and the PS group included 31 patients. C2-7 cervical lordosis, modified Japanese Orthopedic Association (mJOA) scores, neck disability index (NDI) and visual analog scale (VAS) assessments of the groups were compared. Complications were noted and analyzed in detail.

Results: In the PS group, change in C2-7 lordosis was found to be significantly higher than the LMS group ( $p<0.001)$. Changes in quality of life indices (mJOA, NDI and VAS) in the postoperative period did not show a significant difference between LMS and PS groups ( $p=0.608, p=0.224$ and $p=0.296)$. In the study group, 10 complications were observed in 63 patients $(10 / 63,15.8 \%)$. Implant related complication ratio was found to be significantly higher in the LMS group.

Conclusion: Both of the posterior instrumentation methods revealed similar results in terms of quality of life indices. In this study, better results were obtained in the PS group in terms of C2-7 lordosis and implant-related complications. We think that both methods can be used in CSM treatment, however PS fixation is technically challenging with a long learning curve. Therefore, we have the opinion that it can be applied in selected patients by trained and experienced surgeons.
\end{abstract}

Keywords: Cervical spondylotic myelopathy, lateral mass screw, pedicle screw

\section{INTRODUCTION}

Cervical spondylotic myelopathy (CSM) is a spinal cord disease that causes limitation of movement and poor quality of life in the elderly population. Spinal cord compression develops as secondary to joint, and ligament hypertrophy generally occurs progressively, surgical treatment is recommended in cases with severe myelopathy to stop clinical deterioration ${ }^{(1)}$. Laminectomy with decompression and fusion is generally recommended in patients with axial neck pain and involving the multilevel spinal cord (level 3 and above) disease ${ }^{(2)}$. Lateral mass screwing (LMS) is commonly used for posterior fixation. LMS was first applied in 1979 by Roy-Camille and quickly gained widespread popularity in the spine community ${ }^{(3)}$. The most important advantage is that it provides an effective fixation and low neurovascular injury rate $\mathrm{e}^{(3-5)}$. However, the fact that the screw placed in the lateral mass has a short bone-screw purchase worries clinicians about implant failure ${ }^{(6-8)}$. Another posterior instrumentation method, pedicle screwing (PS), was first used by Abumi et al. ${ }^{(9)}$ in trauma surgery in 1990. By this method, screws are placed to the pedicles, the strongest part of the vertebra and a strong anchor is created as in the thoracic and lumbar region. The point that major concern of most surgeons is the risk of vertebral artery injury and root damage ${ }^{(10,11)}$. Therefore, it is not preferred as widely as LMS.

In this study, we examined the clinical results of two posterior instrumentation methods in multilevel CSM surgical treatment 
in terms of radiological, quality of life indices and complications, and we aimed to share the clinical results.

\section{MATERIALS AND METHODS}

This study had been carried out in accordance with principles of the Declaration of Helsinki and approved by Ethics Committee of Adana City Training and Research Hospital. Informed patient consent was obtained from all individuals.

\section{Patient Population}

This study was a retrospective analysis of patients with multilevel CSM disease who underwent decompression with total laminectomy and posterior internal fixation with LMS or PS fixation in the period January 2014 to February 2019. The inclusion criteria were: in at least 3 consecutive levels of spinal cord compression in magnetic resonance imaging (MRI), hyperintense changes in T2 sequence consistent with myelopathy, accompanying neck pain, neurological examination findings consistent with myelopathy. Exclusion criteria were; previous anterior/posterior decompression or fusion and signs of pointing a motor neuron disease or polyneuropathy in electromyography.

The study included 63 cases, and the patients were divided into two groups. The cases in which preoperative cervical lordosis was preserved were included in the LMS group, while patients whose cervical lordosis deteriorated were included in the PS group. The LMS group comprised 32 patients, and the PS group included 31 patients.

\section{Surgical Procedures}

All operations were performed by the same senior spine surgeon. LMS was performed following posterior midline incision, bilateral subperiosteal muscle dissection and facet joints were exposed. The superior lateral ventral corner parallel to the facet joints was targeted by entering a $2 \mathrm{~mm}$ high-speed burr drill from the midpoint of the lateral mass. Screws (PIRON/ IZMIR/TURKEY) were all $4 \mathrm{~mm}$ in diameter and 10-14 $\mathrm{mm}$ in length. Cobalt chromium ( $\mathrm{Co}-\mathrm{Cr}$ ) rods were preferred.

PS fixation were performed with free-hand technique under fluoroscopy guidance and the screw entry point is identified as Abumi et al. ${ }^{(12)}$ defined. PS (PIRON/IZMIR/TURKEY) diameters were $4 \mathrm{~mm}$ in size, length of screws ranged between $24-38 \mathrm{~mm}$ and $\mathrm{Co}-\mathrm{Cr}$ rods were preferred.

All patients underwent total laminectomy in selected levels. While performing decompression in the LMS group, care was taken that the facetectomy should not exceed $50 \%$ of facet joints to not cause further instability ${ }^{(13,14)}$. In the PS group, 2-level ponte osteotomy was performed at C4-5 and C5-6 levels for prophylactic foraminotomy ${ }^{(15)}$. C5 roots were widely decompressed. This procedure was performed to prevent the development of postoperative $\mathrm{C} 5$ palsy.

Following screw fixation, posterior cortex of lateral masses were decorticated and fusion with autografts (harvested from lamina) performed. While rods were placed in both groups, the head side of the operating table was raised, and rods were placed on the screw heads under compressive force to create a lordotic posture to neck. Neurological damage was tried to be prevented by checking the simultaneous intraoperative neuromonitorisation (IONM) recording.

IONM was used in both LMS and PS groups to detect spontaneous physiological changes by recording during the surgical period.

\section{Radiological Assessment}

All patients had symptomatic multilevel CSM with neck pain, confirmed by MRI. Computerised tomography imaging, cervical hyperflexion-hyperextension radiographs and anteroposterior and lateral radiographs were performed preoperatively. Only the preoperative and final postoperative radiographs were included for evaluation due to the length of the follow-up time. Radiographic parameters included C2-7 lordosis.

\section{Clinical Outcomes}

Modified Japanese Orhtopedic Association (mJOA) score, neck disability index (NDI) and visual analog scale (VAS) assessments were performed to patients preoperatively and postoperatively to assess the health-related quality indices and patient comfort. We compared the results of mJOA, NDI and VAS scores preoperatively and the last follow-up postoperatively due to the length of the study.

Apart from surgical complications such as infection and postoperative haematoma, implant related mechanical complications (screw pull-out, screw loosening, screw breakage, rod breakage) and neurovascular injury were assessed and compared. Patients without mechanical complication were considered in favor of fusion.

\section{Statistical Analysis}

Statistical evaluation was performed using the Statistical Package for Social Sciences (SPSS) for Windows 20 (IBM SPSS Inc., Chicago, IL) program. The normal distribution of the data was evaluated with the Kolmogorov-Smirnov test. Normally distributed numerical variables were shown as mean \pm standard deviation, while numerical variables not showing normal distribution were shown as median (minimum, maximum). Categorical variables were expressed as numbers and percentages. Student t-test was used for comparing numerical variables showing normal distribution between the two groups, and Mann-Whitney $\mathrm{U}$ test was used for comparing numerical variables that did not show normal distribution. Chi-square and Fisher's exact Chi-square test were used for comparison of categorical data. For the comparison of preand postoperative changes, repeated mixed model analysis was used. The relationship between the postoperative change percentages (\%) of radiographic parameters and quality of life indices was evaluated with Spearman correlation analysis.

\section{RESULTS}

Sixty-three CSM patients with 32 LMS and 31 PS screws were included in the study population. The mean age of the patients 
was $62.2 \pm 8.6,57.2 \%(n=37)$ were male, $42.8 \%(n=26)$ were female. The median follow-up interval of the patients was 26 (17-46) months. The demographic characteristics, preoperative radiological findings and quality of life indices of the patients are shown in detail in Table 1.

In PS group, C2-7 lordosis change was found to be significantly high with respect to LMS group ( $p<0.001$ ) (Table 2).

Significant improvement was found in C2-7 lordosis and quality of life indices (mJOA, NDI and VAS) postoperatively in all patients (Table 2).

Changes in quality of life indices (mJOA, NDI and VAS) postoperatively did not differ significantly between the LMS and PS groups ( $p=0.608, p=0.224, p=0.296$ ) (Table 2).

In the study group, complications were observed in 10 patients with a ratio of $15.8 \%(10 / 63)$. Screw loosening was seen in 4 patients (12.5\%) in the LMS group, these patients underwent revision surgery and revised with PS's. In LMS group no screw or rod fracture was observed. Upon the development of superficial wound infection in 1 patient (3.1\%), debridement was performed under local anesthesia and antibiotherapy was applied according to the wound culture result. Direct neurovascular injury was not observed. C5 palsy was observed in 2 patients (6.2\%) after the second postoperative day. Complete recovery was achieved at the end of the first month following the physical therapy and rehabilitation programme.

No screw loosening, screw or rod fracture was observed in the PS group. C5 palsy was observed in 2 patients (6.4\%) after the second postoperative day. With appropriate physiotherapy, complete recovery was achieved in the patients within 1 month. One patient underwent debridement due to superficial wound infection. Implant-related revision surgery was not performed. Vertebral artery injury or spinal cord direct injury was not found. In LMS group, implant related complications are found to be significantly high with respect to PS group $(p<0.05)$ Table 3.

\section{DISCUSSION}

CSM is a progressive disease that causes spinal cord dysfunction, causing gait disorders and weakness in the upper and lower extremities. In this clinical status where medical treatment is not effective, surgical strategies are applied. The main purpose of surgical treatment is to stop progression of disease and provide an effective decompression ${ }^{(16)}$. General opinion in decompression surgery is such that if the spinal cord is compressed from the anterior, it is usually relieved from pressure anteriorly, if the compression is from the

Table 1. Distribution of demographic and clinical findings

\begin{tabular}{|c|c|c|c|c|}
\hline Variables & All population $(n=63)$ & LMS $(n=32)$ & PS $(n=31)$ & $\mathbf{p}$ \\
\hline \multicolumn{5}{|l|}{ Age, years } \\
\hline Mean \pm SD & $62.2 \pm 8.6$ & $63.9 \pm 8.8$ & $62.5 \pm 7.6$ & \multirow{2}{*}{0.693} \\
\hline Min-max & $49-77$ & $49-72$ & $49-77$ & \\
\hline \multicolumn{5}{|c|}{ Gender, n (\%) } \\
\hline Female & $27(42.8)$ & $16(50.0)$ & $9(29)$ & \multirow{2}{*}{0.324} \\
\hline Male & $36(57.2)$ & $16(50.0)$ & $22(71)$ & \\
\hline \multicolumn{5}{|c|}{ Follow-up period $(\mathrm{m})$} \\
\hline Median & 26 & 26.5 & 25 & \multirow{2}{*}{0.116} \\
\hline Min-max & $17-46$ & $24-46$ & $17-33$ & \\
\hline \multicolumn{5}{|c|}{ Preoperative $\mathrm{C} 2-7$ lordosis ( ${ }^{\circ}$ ) } \\
\hline Median & 2 & 3 & 0 & \multirow{2}{*}{0.019} \\
\hline Min-max & $(-10)-10$ & (0)-10 & $(-10)-3$ & \\
\hline \multicolumn{5}{|l|}{$\mathrm{mJOA}$} \\
\hline Mean \pm SD & $9.1 \pm 2.5$ & $9.2 \pm 2.5$ & $9.0 \pm 1.4$ & \multirow{2}{*}{0.824} \\
\hline Min-max & $7-13$ & $7-13$ & $7-13$ & \\
\hline \multicolumn{5}{|l|}{ VAS } \\
\hline Mean \pm SD & $8.2 \pm 0.8$ & $7,9 \pm 0.9$ & $8.3 \pm 0.8$ & \multirow{2}{*}{0.327} \\
\hline Min-max & $6-9$ & $6-9$ & $7-9$ & \\
\hline \multicolumn{5}{|l|}{ NDI } \\
\hline Median & 30 & 28 & 30 & \multirow{2}{*}{0.817} \\
\hline Min-max & $20-38$ & $20-38$ & $21-38$ & \\
\hline
\end{tabular}

Numerical variables with normal distribution were shown as mean \pm SD.

Numerical variables that do not show normal distribution are shown as median.

Categorical variables were shown as numbers (\%).

LMS: Lateral mass screw, PS: Pedicle screw, mJOA: Modified Japanese Orthopedic Association, VAS: Visual analog scale, NDI: Neck disability index, SD: Standard deviation, Min: Minimum, Max: Maximum 
Table 2. Postoperative change of radiographic parameters and quality of life indices

\begin{tabular}{|c|c|c|c|c|c|c|c|c|c|c|}
\hline \multirow{2}{*}{ Variables } & \multicolumn{2}{|c|}{ All population $(n=63)$} & \multirow{2}{*}{ p } & \multicolumn{2}{|l|}{ LMS (n=32) } & \multirow[t]{2}{*}{$\mathrm{p}$} & \multicolumn{2}{|l|}{ PS (n=31) } & \multirow[t]{2}{*}{$\mathbf{p}$} & \multirow[t]{2}{*}{$\Delta p$} \\
\hline & Preoperative & Postoperative & & Preoperative & Postoperative & & Preoperative & Postoperative & & \\
\hline \multicolumn{11}{|l|}{$\mathrm{C} 2-7\left(^{\circ}\right)$} \\
\hline Median & 2 & 10 & \multirow{2}{*}{$<0.001^{*}$} & 3 & 6 & \multirow{2}{*}{$<0.001^{*}$} & 0 & 9 & \multirow{2}{*}{$<0.001^{*}$} & \multirow{2}{*}{$<0.001^{*}$} \\
\hline Min-max & $(-10)-10$ & $0-18$ & & (0)-10 & $0-16$ & & $(-10)-3$ & $3-18$ & & \\
\hline \multicolumn{11}{|l|}{$\mathrm{mJOA}$} \\
\hline Mean \pm SD & $9.1 \pm 2.5$ & $13.3 \pm 1.3$ & \multirow{2}{*}{$<0.001^{*}$} & $9.2 \pm 2.5$ & $13.1 \pm 1.1$ & \multirow{2}{*}{$<0.001^{*}$} & $9.0 \pm 1.4$ & $13.4 \pm 1.5$ & \multirow{2}{*}{$<0.001^{*}$} & \multirow{2}{*}{0.608} \\
\hline Min-max & $7-13$ & $11-16$ & & $7-13$ & $11-16$ & & $7-13$ & $11-16$ & & \\
\hline \multicolumn{11}{|l|}{ VAS } \\
\hline Mean \pm SD & $8.2 \pm 0.8$ & $3.4 \pm 1.3$ & \multirow{2}{*}{$<0.001^{*}$} & $7,9 \pm 0.9$ & $3.5 \pm 1.3$ & \multirow{2}{*}{$<0.001^{*}$} & $8.3 \pm 0.8$ & $3.6 \pm 1.3$ & \multirow{2}{*}{$<0.001^{*}$} & \multirow{2}{*}{0.296} \\
\hline Min-max & $6-9$ & $2-6$ & & $6-9$ & $2-6$ & & $7-9$ & $2-6$ & & \\
\hline \multicolumn{11}{|l|}{ NDI } \\
\hline Median & 30 & 17 & \multirow{2}{*}{$<0.001^{*}$} & 28 & 18 & \multirow{2}{*}{$<0.001^{*}$} & 30 & 15 & \multirow{2}{*}{$<0.001^{*}$} & \multirow{2}{*}{0.224} \\
\hline Min-max & $20-38$ & $8-34$ & & $20-38$ & $8-34$ & & $21-38$ & $8-34$ & & \\
\hline
\end{tabular}

Numerical variables with normal distribution were shown as mean \pm SD.

Numerical variables that do not show normal distribution are shown as median.

* $p<0.05$ shows statistical significance.

$\Delta p$ shows statistical significance of preoperative and postoperative differences between groups ( $\triangle$ MASS vs $\triangle$ Pedicule)

LMS: Lateral mass screw, PS: Pedicle screw, mJOA: Modified Japanese Orthopedic Association, VAS: Visual analog scale, NDI: Neck disability index, SD: Standard deviation,

Min: Minimum, Max: Maximum

Table 3. Evaluation of complications between groups

\begin{tabular}{llll}
\hline & $\begin{array}{l}\text { Implant related } \\
\text { complications (screw } \\
\text { loosening) }\end{array}$ & $\begin{array}{l}\text { Infection } \\
(\%)\end{array}$ & $\begin{array}{l}\text { C5 palsy } \\
(\%)\end{array}$ \\
\hline LMS $(\mathrm{n}=32)$ & $4(12.5)$ & $1(3.1)$ & $2(6.2)$ \\
\hline PS $(\mathrm{n}=31)$ & $0(0)$ & $1(3.2)$ & $2(6.4)$ \\
\hline$p$-value & $p<0.05$ & $p>0.05$ & $p>0.05$ \\
\hline $\begin{array}{l}\text { p }<0.05 \text { shows statistical significance. } \\
\text { LMS: Lateral mass screw, PS: Pedicle screw }\end{array}$ & & \\
\hline
\end{tabular}

posterior, the spinal cord is decompressed from the posterior. However, this is not always the case. Posterior approaches are generally preferred in cases with multi-level spinal cord compression ${ }^{(2)}$. While deciding on a posterior approach, detailed questioning of the need for instrumentation is important to prevent complications such as instability and postlaminectomy kyphosis. More complex surgical procedures may be required if postlaminectomy kyphosis occurs in patients with spinal cord dysfunction $^{(17,18)}$.

Laminoplasty, one of the cervical posterior instrumentation methods, can be used in cases where cervical lordosis is preserved ${ }^{(19,20)}$. However, in cases with neutral or kyphotic cervical curvature, additional fusion is recommended if there is accompanying neck pain ${ }^{(2)}$. The two effective methods at this point are LMS and $\mathrm{PS}(2,6,21,22)$. LMS is the most preferred posterior instrumentation method preferred by spinal surgeons. Fixation is provided by screws placed in the lateral mass of the cervical vertebra (Figure 1). The risk of nerve root damage and vertebral artery injury is $\operatorname{low}^{(3-5)}$. The main concern with LMS is related to the strength of the $\mathrm{screw}^{(7,23)}$. This situation causes weakness in

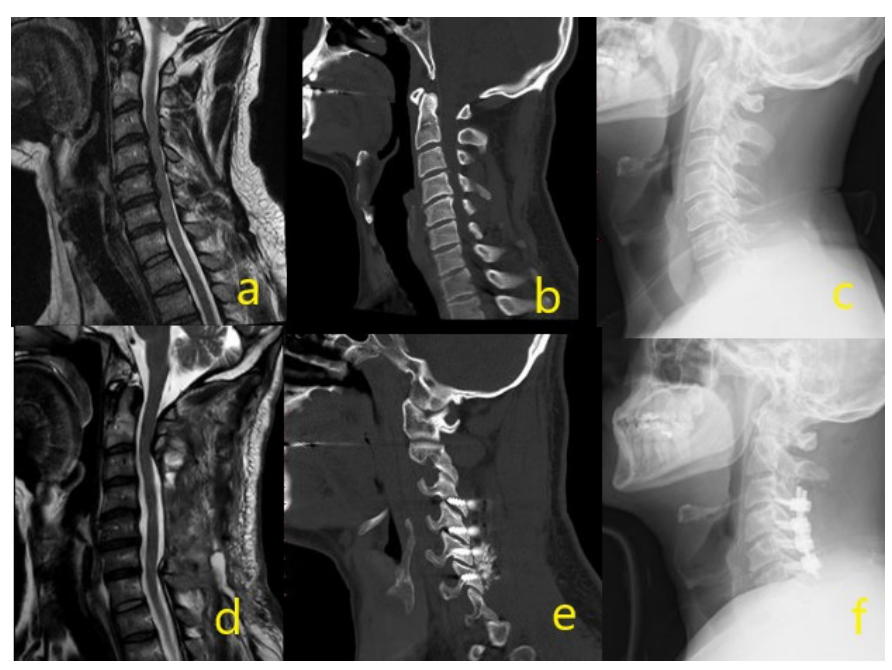

Figure 1. Radiological images of the 58-year-old male patient with CSM who underwent total laminectomy with decompression + lateral mass fixation between C3-6 are shown above. Preoperative magnetic resonance, computed tomography, and lateral X-ray images are demonstrated between $a-c)$. In $d-f$ ) images, postoperative images are displayed on MRI, CT and direct lateral radiography, respectively.

CSM: Cervical spondylotic myelopathy, MRI: Magnetic resonance imaging, $\mathrm{CT}$ : Computed tomography

pathologies that require rigid fixation. PS, on the other hand, provides strong anchor strength and stabilization by reaching the anterior of the vertebra through the pedicle ${ }^{(24)}$ (Figure 2). Its major disadvantage is the risk of nerve root injury and vertebral artery injury ${ }^{(6)}$. 
In this study, we examined the clinical results of both methods in terms of cervical lordosis, quality of life indices and complications. In the study of Sielatycki et al.(25), decompression and fusion with LMS were applied to 45 patients with CSM, and as a result of the study, a significant $3.6^{\circ}$ improvement was found in the C2-7 cobb angle ${ }^{(25)}$. In another study, Abumi et al. (24) reported the results of cervical kyphosis treatment with PS's, and kyphosis was divided into 2 groups as flexible and rigid/ fixed. The kyphosis angle was measured radiologically, and approximately $23^{\circ}$ correction was obtained postoperatively. In our study, we obtained similar results parallel to the literature mentioned above. Radiologically, there was a significant improvement in C2-7 lordosis values in both groups. When compared between the groups, the improvement was better in the PS group. We attribute this to the ponte osteotomies we performed for prophylactic foraminotomy. It can be explained why the improvement in C2-7 lordosis is better in the PS group with this process, which provides a gain of approximately $5^{\circ}$ at each level. Another reason may be that when performing decompression in the LMS group, care was taken that facetectomies did not exceed $50 \%$ in order to not to increase instability (Table 4).

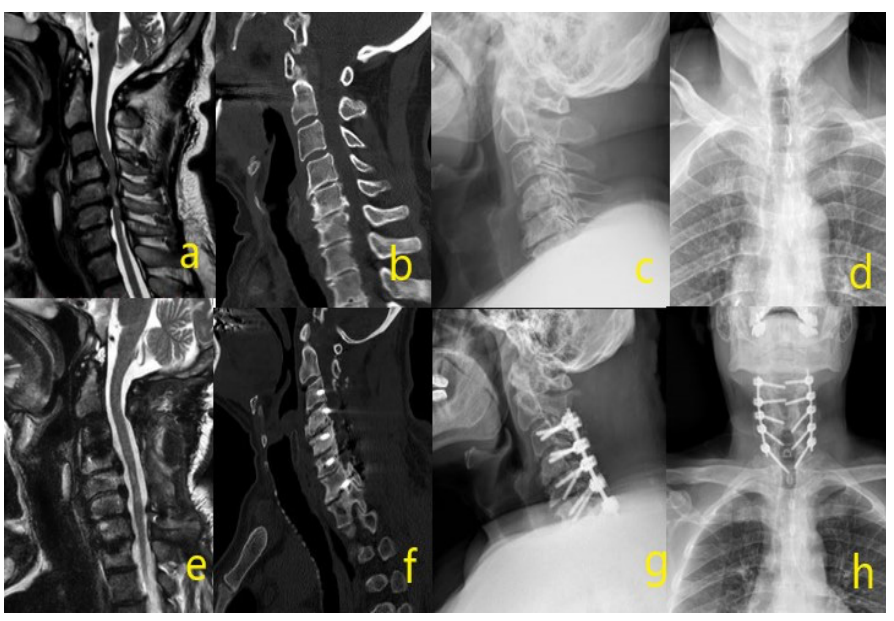

Figure 2. A 61-year-old male patient with multilevel CSM underwent decompression + PS fixation between C3-7. Preoperative MRI, $\mathrm{CT}$ and direct $\mathrm{x}$-ray images are seen on images between a-d). Postoperative images are seen in images between e-h). e) MRI shows that the spinal cord compression has disappeared completely.

CSM: Cervical spondylotic myelopathy, PS: Pedicle screw, MRI: Magnetic resonance imaging, CT: Computed tomography

Table 4. Levels and numbers of total laminectomy and ponte osteotomy

\begin{tabular}{lll}
\hline Levels & Total laminectomies & Ponte osteotomy \\
\hline C2-3 & 78 & - \\
\hline C3-4 & 81 & - \\
\hline C4-5 & 63 & 31 \\
\hline C5-6 & 63 & 31 \\
\hline C6-7 & 21 & - \\
\hline Total & 306 & 62 \\
\hline
\end{tabular}

Several studies have been published reporting improvement in quality of life after fusion with laminectomy in multilevel CSM treatment ${ }^{(25-28)}$. In the study of Sielatycki et al.(25), 45 patients underwent laminectomy with decompression and fusion with the lateral mass, and at the end of 1 year, significant improvement was obtained in NDI and mJOA scores. In the study conducted by Blizzard et al. ${ }^{(28)}$ where they compared laminoplasty with laminectomy + fusion (LMS) in patients with CSM, 31 patients were applied laminectomy + fusion, and it was reported that there was a significant improvement in JOA and VAS scores ${ }^{(28)}$. In the study of Du et al. ${ }^{(29)}, 41$ patients with multilevel cervical degenerative myelopathy were evaluated. The study, which reported a mean follow-up of 2.8 years, found significant improvement in JOA and VAS scores in patients who underwent laminectomy with fusion (LMS). In another study reporting 18 months follow-up results of 48 patients, Chang et al. applied posterior instrumentation (LMS) with laminectomy a significant improvement was observed in JOA score. Kotil et al. ${ }^{(30)}$ found a significant improvement in Nurick scores in the study in which patients with CSM have applied decompression with posterior fixation (PS). In another study, Abumi et al. ${ }^{(32)}$ reported the results of one-stage surgery with PS in patients with myelopathy. Neurological status evaluation was made according to Frankel staging and no worsening was observed in the postoperative period in any patient, while improvement was detected in 26 of 46 patients. In this study, considering the literature data reported above, we think that the results obtained in both groups are satisfactory in terms of quality of life scores. When we compared the results of both groups in terms of mJOA, NDI and VAS, we could not find a significant difference. We think the reason for this is the sufficient stability was accomplished and adequate decompression had been provided.

Some complications were encountered in the study cohort. Screw loosening was seen as an implant-related complication in 4 patients in the LMS group, and these patients underwent revision surgery by placing PS's. There were no implant-related complications in the PS group. In the biomechanical study of Johnston et al.(23), LMS and PS were compared, while the percentage of loosening in the bone-screw interface of PS's was found to be low, the strength was found to be higher in the fatigue test. In the biomechanical study of Ito et al. ${ }^{(8)}$, LMS and PS were compared under the effect of torsion and flexionextension forces. PS's were found to have 4 times stronger pullout strength in the torsion group and 2 times stronger in the flexion-extension group. In this study, a result supporting the above literature was obtained. While no pull-out or loosening was observed in the PS group, 4 patients in the LMS group had screw loosening.

Superficial wound infection developed in both groups in 2 patients and they were given medical treatment with locally administered surgical debridement. No vertebral artery damage or direct root injury was observed in both groups. There were no neurological deficits due to spinal cord injury however $\mathrm{C} 5$ 
palsy was observed both in 2 patients in LMS and PS group postoperatively 48 hours. We do not know the exact cause of C5 palsy, but we think that the tension in the root due to spinal cord shift after decompression caused this situation. Many articles have reported the development of C5 palsy as a result of posterior cervical surgery, and the rate for this has been reported as $5-14 \%{ }^{(33,34)}$. In this study, this rate was found to be $6.4 \%$. Considering the current literature data, our C5 palsy complication rate is parallel to the literature.

\section{Study Limitations}

There are many limitations to this study. The first one of these is the retrospective design. Secondly, radiographic parameters could be analyzed in more detail and their correlation with quality of life indices could be questioned. The strength of the study is that it analyzed two different posterior fixation techniques demographically, radiologically and clinically in similar patient groups.

\section{CONCLUSION}

Both posterior instrumentation methods showed similar results in terms of quality of life indices. In this study, better results were obtained in the PS group in terms of C2-7 lordosis and implant-related complications. We think that both methods can be used in CSM treatment, but the PS application technically difficult and has a long learning curve. Therefore, we believe that it can be applied by skilled and experienced surgeons in selected cases.

\section{Ethics}

Ethics Committee Approval: This study had been carried out in accordance with principles of Declaration of Helsinki and approved by Ethics Committee of Adana City Training and Research Hospital (date: 15.01.2020, decision no: 690).

Informed Consent: Informed consent was obtained from all individual participants included in the study.

Peer-review: Internally peer-reviewed.

\section{Authorship Contributions}

Concept: S.K.O., A.A., S.B.K., V.A., B.A., Y.G., A.I.Ö., Design: S.K.O., A.A., S.B.K., V.A., B.A., Y.G., A.I.Ö., Data Collection or Processing: A.A., S.K.O., S.B.K., V.A., B.A., Y.G.,A.I..Ö., Analysis or Interpretation: A.A., S.K.O., S.B.K.,V.A., B.A., Y.G., A.I.Ö., Literature Search: S.K.O., A.A., S.B.K.,V.A., B.A., Y.G., A.I.Ö., Writing: S.K.O., A.A., S.B.K., V.A., B.A., Y.G., A.I.Ö.

Conflict of Interest: The authors declared that this study received no financial support.

Financial Disclosure: The authors have no conflicts of interest to declare.

\section{REFERENCES}

1. Zileli M, Borkar SA, Sinha S, Reinas R, Alves O, Kim S, et al. Cervical spondylotic myelopathy: natural course and the value of diagnostic techniques -wfns spine committee recommendations. Neurospine. 2019;16:386-402.
2. Bajamal AH, Kim SH, Arifianto MR, Faris M, Subagio E, Roitberg B, et al. posterior surgical techniques for cervical spondylotic myelopathy: WFNS Spine Committee Recommendations. Neurospine. 2019;16:421-34.

3. Roy-Camille, R, Saillant GMC. Internal fixation of the unstable cervical spine by a posterior osteosynthesis with plates and screws In: Sherk H (Ed). The cervical spine. Lippincott, Philadelphia, 1989;pp:390-403.

4. Yoshihara H, Passias PG, Errico TJ. Screw-related complications in the subaxial cervical spine with the use of lateral mass versus cervical pedicle screws :a systematic review. J Neurosurg Spine. 2013;19:614-23.

5. Kwon BK, Vaccaro AR, Grauer JN, Beiner JM. The use of rigid internal fixation in the surgical management of cervical spondylosis. Neurosurgery. 2007;60(Suppl 1):S118-29.

6. Tukkapuram VR, Kuniyoshi A, Ito M. A review of the historical evolution, biomechanical advantage, clinical applications, and safe insertion techniques of cervical pedicle screw fixation. Spine Surg Relat Res. 2019;3:126-35.

7. Jones EL, Heller JG, Silcox DH, Hutton WC. Cervical pedicle screws versus lateral mass screws: Anatomic feasibility and biomechanical comparison. Spine (Phila Pa 1976). 1997;22:977-82.

8. Ito Z, Higashino K, Kato S, Kim S, Wong E, Yoshioka K, et al. Pedicle screws can be 4 times stronger than lateral mass screws for insertion in the midcervical spine: a biomechanical study on strength of fixation. J Spinal Disord Tech. 2014;27:80-5.

9. Abumi K, Itoh H, Taneichi H, Kaneda K. Transpedicular screw fixation for traumatic lesions of the middle and lower cervical spine: Description of the techniques and preliminary report. J Spinal Disord. 1994;7:19-28.

10. Abumi K, Shono Y, Ito M, Taneichi H, Kotani Y, Kaneda K. Complications of pedicle screw fixation in reconstructive surgery of the cervical spine. Spine. 2000;25:962-9.

11. Abumi K, Kaneda K. Pedicle screw fixation for nontraumatic lesions of the cervical spine. Spine (Phila Pa 1976). 1997;22:1853-63.

12. Abumi K, Ito $M$, Sudo $H$. Reconstruction of the subaxial cervical spine using pedicle screw instrumentation. Spine (Phila Pa 1976). 2012;3711:E349-56. doi: 10.1097/BRS.0b013e318239cf1f.

13. Choi SH, Kang C-N. Degenerative cervical myelopathy: pathophysiology and current treatment strategies. Asian Spine J. 2020;14:710-20.

14. Zdeblick TA, Ducker TB. The use of freeze-dried allograft bone for anterior cervical fusions. Spine (Phila Pa 1976). 1991;16:726-9.

15. Ames CP, Smith JS, Scheer JK, Shaffrey C, Lafage V, Deviren V, et al. A standardised nomenclature for cervical spine soft-tissue release and osteotomy for deformity correction. I Neurosurg Spine. 2013;19:269-78

16. Istemen I, Ozdogan S, Duzkalir AH, Senturk S, Yildirim T, Okutan MO. Clinical results of median corpectomy in cervical spondylotic patients with myelopathy. Turk Neurosurg. 2016;26:90-6.

17. Deutsch H, Haid RW, Rodts GE, Mummaneni PV. Postlaminectomy cervical deformity. Neurosurg Focus. 2003;15:E5. doi: 10.3171/ foc.2003.15.3.5.

18. Albert TJ, Vacarro A. Postlaminectomy kyphosis. Spine (Phila Pa 1976). 1998;23:2738-45.

19. Yoon ST, Hashimoto RE, Raich A, Shaffrey $\mathrm{Cl}$, Rhee JM, Riew KD. Outcomes after laminoplasty compared with laminectomy and fusion in patients with cervical myelopathy. Spine (Phila Pa 1976). 2013;38:S183-94.

20. Chen C, Yang C, Yang S, Gao Y, Zhang Y, Wu X, et al. Clinical and radiographic outcomes of modified unilateral open-door laminoplasty with posterior muscle-ligament complex preservation for cervical spondylotic myelopathy. Spine (Phila Pa 1976). 2019;44:1697-704.

21. Coe JD, Vaccaro AR, Dailey AT, Skolasky R, Sasso R, Ludwig S, et al. Lateral mass screw fixation in the cervical spine a systematic literature review. J Bone Joint Surg Am. 2013;95:2136-43. 
turkishspine

22. Joaquim AF, Tan L, Riew KD. Posterior screw fixation in the subaxial cervical spine: a technique and literature review. J Spine Surg. 2020;6:252-61.

23. Johnston TL, Karaikovic EE, Lautenschlager EP, Marcu D. Cervical pedicle screws vs. lateral mass screws: uniplanar fatigue analysis and residual pullout strengths. Spine J. 2006;6:667-72.

24. Abumi K, Shono Y, Taneichi H, Ito M, Kaneda K. Correction of cervical kyphosis using pedicle screw fixation systems. Spine. (Phila Pa 1976). 1999;24:2389-96.

25. Sielatycki JA, Armaghani S, Silverberg A, McGirt MJ, Devin Cl, O’Neill $\mathrm{K}$. Is more lordosis associated with improved outcomes in cervical laminectomy and fusion when baseline alignment is lordotic? Spine J. 2016;16:982-8.

26. Rhee JM, Basra S. Posterior surgery for cervical myelopathy: laminectomy, laminectomy with fusion, and laminoplasty. Asian Spine J. 2008;2:114-26.

27. Singrakhia MD, Malewar NR, Singrakhia SM, Deshmukh SS. Cervical laminectomy with lateral mass screw fixation in cervical spondylotic myelopathy: Neurological and sagittal alignment outcome: do we need lateral mass screws at each segment? Indian J Orthop. 2017; 51:658-65.

28. Blizzard DJ, Caputo AM, Sheets CZ, Klement M, Michael K, Isaacs R, et al. Laminoplasty versus laminectomy with fusion for the treatment of spondylotic cervical myelopathy: short-term follow-up. Eur Spine J. 2017; 26:85-93.
29. Du W, Zhang P, Shen Y, Zhang YZ, Ding WY, Ren LX. Enlarged laminectomy and lateral mass screw fixation for multilevel cervical degenerative myelopathy associated with kyphosis. Spine J. 2014;14:57-64.

30. Chang V, Lu DC, Hoffman H, Buchanan C, Holly LT. Clinical results of cervical laminectomy and fusion for the treatment of cervical spondylotic myelopathy in 58 consecutive patients. Surg Neurol Int. 2014;5(Suppl 3): S133-7. doi: 10.4103/2152-7806.130670.

31. Kotil K, Ozyuvaci E. Multilevel decompressive laminectomy and transpedicular instrumented fusion for cervical spondylotic radiculopathy and myelopathy: a minimum follow-up of 3 years. Craniovertebr Junction Spine. 2011;2:27-31.

32. Abumi K, Kaneda K, Shono Y, Fujiya M. One-stage posterior decompression and reconstruction of the cervical spine by using pedicle screw fixation systems. J Neurosurg. 1999;90(Suppl 1):19-26.

33. Bydon M, Macki M, Kaloostian P, Sciubba D, Wolinsky J, Gokaslan $\mathrm{Z}$, et al. Incidence and prognostic factors of C5 Palsy: A clinical study of 1001 cases and review of the literature. Neurosurgery. 2014;74:595-604.

34. Eskander MS, Balsis SM, Balinger C, Howard C, Lewing N, Eskander J, et al. The association between preoperative spinal cord rotation and postoperative C5 nerve palsy. J Bone Joint Surg Am. 2012;94:1605-9. 